\title{
Social-Environmental Problematic in the Socio-Geographical Space of Lapraka
}

\author{
Msc. Brunilda Osmovi-Bibe
}

High School "Arben Broci" Tirana- Albania

Email: brunaosmovi@yahoo.com

\section{Dr Robert Hykollari}

Doi:10.5901/ajis.2014.v3n3p134

High School "Arben Broci" Tirana- Albania

Email: hykollari@gmail.com

\begin{abstract}
The favorable physical-geographical and social-economic conditions have made Tirana very much attractive for the population of various territories in our country. Borough no: 11 is chosen for habitation by the incomers due to its appropriate regional position, the existence of free land surfaces and low rents. In Borough no: 11, there has been a growing population from year to year affected by the natural child birth and migratory movements. The increase of the population number in this borough has been associated with numerous economic and social problems. After 1990, there has been a construction boom, which gave the borough a view of a more typical suburban area in Tirana, by creating a suburban neighborhood that lacks urban plans. The construction boom was not associated with the infrastructure development. The normal conditions of habitation and infrastructure increase the life quality and as a result they facilitate the contribution of citizens on a sustainable development. The participation of the community in the daily activity, also their focus on the short and long term planning, is a necessity. Despite all the improvements that these last years have been evident, its further improvement is an imperative need for the residents of this borough. A special assistance in this direction is the education and qualification level of the individuals as simple citizens, members of the community, also as professionals.
\end{abstract}

Keywords: Informal areas, lack of services, environmental situation, the equipping with home appliances.

\section{Introduction}

Lapraka as part of the city with its deficiencies as far as development is concerned, represents the suburban problematic of the last urban development in Albania. Borough no: 11 has around 62 thousand residents, 16 production confectionary businesses, shoes businesses, furniture businesses, wood procession, construction materials, 600 entities, 6 schools, 4 nursery schools, four kindergartens, 3 health centers, but on the other hand, there is also great unemployment, where $60 \%$ of the labor power, capable of working, are unemployed. The only models that make Lapraka similar to Tirana are the "Gintash" block of residencies which offer a better looking environment. The rest is different. With a population where over $75 \%$ have come from rural areas, Lapraka cannot escape from some serious problems. In these recent years, the situation has somewhat changed for the better and this is verified by numerous projects implemented in the area.

\section{The Needs and Problems of Borough:11}

The increase of the population number is accompanied with a significant increase of the buildings ' number. This fact is indicated by numerous constructions where high buildings like villas, dominate in the area. Before 1990, part of Lapraka has been only the area that was bordered by "Rruga e Durresit", former "Shoe Factory", Don Bosko Street, the National Road axis Tirana-Fushe-Kruje and Tirana River. This was an industrial-agricultural area which had only a few residential blocks. After 1990, where there was a population influx, there were built 3770 illegal buildings, 97 interventions in flats and 11 buildings 5-7 storey high. In borough $11,70 \%$ of the buildings (residential houses) are in informal areas, 1-3 storeys, mainly of concrete blocks, where the sewage system and the water supply system are presented as very problematic. The Area of Bregu i Lumit has joined Borough 11 after 1993, where there are 1930 houses constructed before 1990, also there are 1370 illegal buildings constructed after 1990. 
Graph 1. Division of families according to the houses they live in, 2011

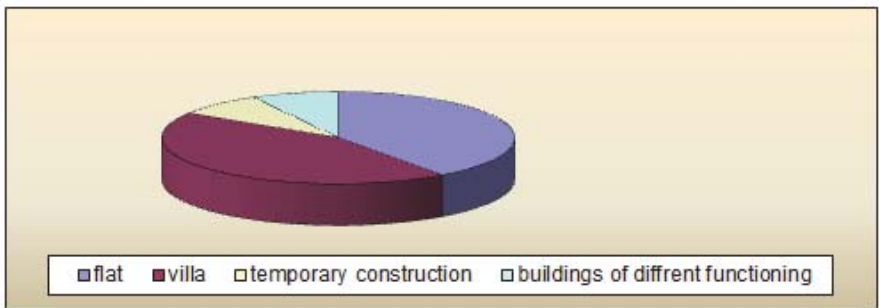

Source: Survey

\subsection{Conditions of accommodation and residence}

As for the type of the houses they live in, from the surveys it resulted that $44 \%$ live in private houses or villas, $40 \%$ in apartments, $8 \%$ in temporary constructions and $8 \%$ in buildings of different functioning from that of living. Two or more families live in such houses "villa type", a phenomenon that is linked to the extended traditional family of two couples (parents+ their son and bride), but even to the phenomenon of the lack of the free spaces for construction. As for the construction boom, after 1990, it resulted that the period of the construction boom was linked to the considerable number of incomers.

Around $72 \%$ of the interviewers result to be owners and $28 \%$ are tenants. The high percentage of the families that are owners of their houses is a premise to not cause the movement of the population from one area to another. As a matter of fact, not everything comes as you expect. The studies over the population movement in town show that the movements may be voluntary and involuntary. Involuntary movements come as a result of the property losses, marriages, divorces, deaths in families or big distances between home and the workplace, whereas the voluntary movements are associated with various factors such as living conditions, environment, and personal reasons.

As for the house surfaces, nearly half of the interviewers live in a surface of 40-69 square meters, whereas the maximal and minimal surface (40 square meters-130 square meters) have almost the same percentage.

Graph 2. Division of the houses according to the surface of their houses

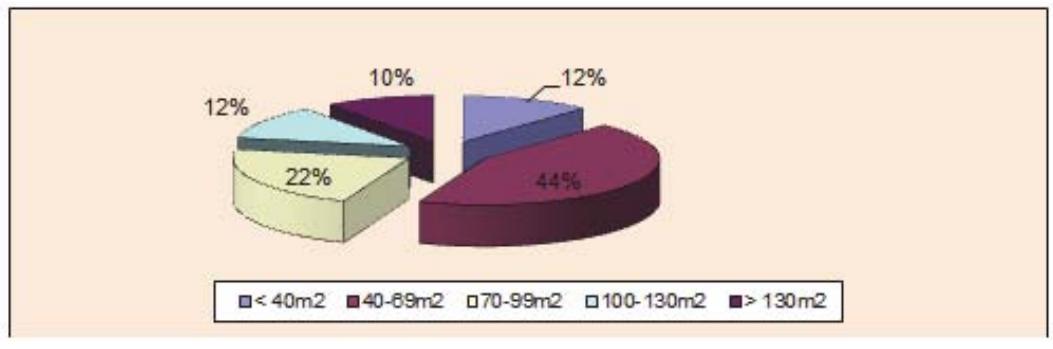

\section{Source: Survey}

As for the number of the rooms, more than half of the families live in 2 or 3 rooms (61\%), whereas the percentage of the families that live in 5,6 or 8 rooms (19\%) is linked to the high buildings (villa type), where an extended family lives and the percentage of the families that live in a room is $7 \%$ and belongs to the temporary buildings and to those who live in school buildings.

\subsection{Social-environmental problems}

The massive uncontrolled movement of the population towards Tirana has not been associated with the construction of the necessary infrastructure. As a matter of fact, various problems have been identified in these informal areas of the city that have to do with the lack of services; a) water supply; b) roads construction, c) water services and water purity, d) new 
health centers for healthcare, education centers, etc. The problems that are linked with the basic unfulfilled needs are mainly present in the poor areas of Tirana and especially in its suburbs. They have aggravated even more as a result of the social and health culture of the newly incomers, the big number of children in a family, inappropriate living areas, lack of the hygienic conditions, lack of water supply which make them subject to epidemics. As far as the supply with water is concerned, about $60 \%$ of the interviewers are supplied with drinking water in their house, and $12 \%$ provide water outside the house, $22 \%$ provide water from water wells and $6 \%$ were not supplied with water at all. The situation of water supply appears even more concerning in Kodër-Kamëz and Bregu i Lumit neighborhoods. These neighborhoods are supplied with water only three hours a day, whereas in Lapraka neighborhood, the lack of water during 24 hours is 8-9 hours.

Graph 3. Division of the families according to the supply with water

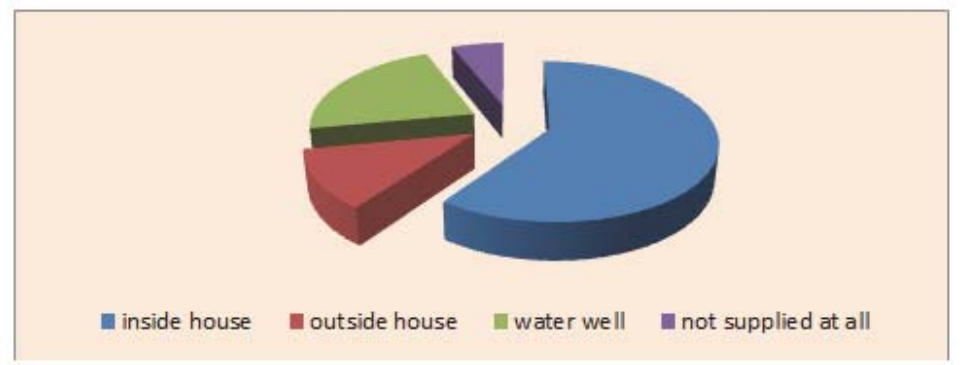

Source: Survey

Even the situation of sewages is presented problematic; the half of the interviewers possess hygiene and sanitary equipment, whereas the percentage of the families that own two hygiene and sanitary equipment is $10 \%$ of the respondents. The high percentage of the lack of water filtering plants (around 40\%) witnesses about the situation of the sewage system in the area. However, the situation has significantly improved in comparison to 1990-2001 and thanks to the considerable investments made by the local and central power, there is still much to be done. As far as heating is concerned, the majority of the population provides individual heating, whereas central heating comprises a very small percentage.

The high percentage of the interviewers that use individual heating is based on wood stoves, a fact that is linked to the difficult economic situation, also with the traditional way of the incomers' living. A considerable percentage comprises even the number of families that don't use heating due to the economical difficulties, because they have to afford the high electricity bills, gas and wood as well.

As far as the electrical appliances are concerned in Borough 11, many families choose to buy the main electrical appliances first, such as TV, fridges, washing machines and then the others. The other appliances such as computer, air conditioner are still considered luxurious and only a small number of the families have them. Having a car is a privilege of a relatively small part of the population for every borough, even for borough 11, the number of families that own a car is relatively small. Many families that own a car do not use it due to the high price of fuel.

Graph 4. Division of the families according to the possession of the electric appliances, 2011

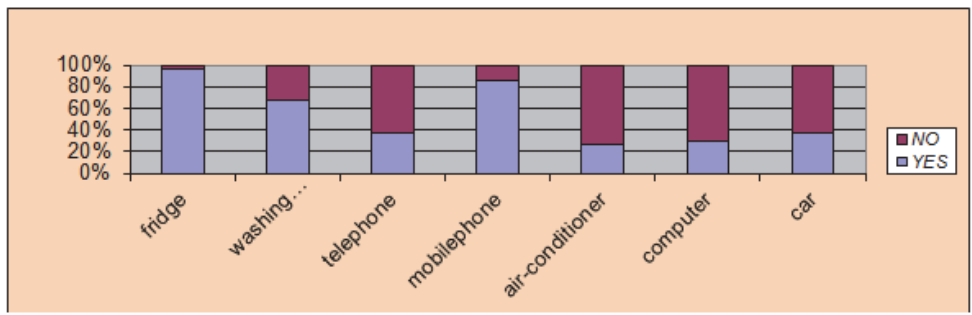

Source: Survey 
As for the question whether they used any means of transport, it resulted that the best part uses public transport, even the private one, mainly the residents of "Koder-Kamez" and "Bregu i Lumit" neighborhoods. There are three bus lines that operate in Borough 11; Laprakë - Tirana center, Agricultural University -Tirana center and "New Ring", where the latter serves mostly to the residents of Lapraka neighborhood. The lines which are on demand are "Ura e Kamzës-Paskuqan, Breg Lumas- Tirana center, which in fact are covered by private means of transport.

Another problem is even the equipping of the families with telephones. According to the respondents, only $38 \%$ of the families had a telephone at home, however the problem has somewhat alleviated due to the equipping with mobile phones, which has become the major means of communication.

\subsection{Environmental problems}

Some concerning problem for the residents of Borough 11 as well as for the citizens that live in Tirana are dust, gases, waste and inert, the unpaved roads, etc. A good job has been done by the borough for the increasing number of the garbage containers, but more is expected by the borough as it covers only $90 \%$ of the urban waste.

A great concern for the residents of the borough is Tirana River, which is exposed to great pollution due to its bed damage and sewage spill. In Borough 11, there are 150 Roma families that comprise around 1200 residents who live along Tirana River shore. Dozens of Roma people`s houses are flooded every time it rains heavily in the area. Tirana River bursts out of its bed and floods their houses, whereas residents try to escape the floods and survive. Some of the Roma families are accommodated to the relatives' houses, whereas others pass the night in open sky.

The sewage system comprises another concern in Lapraka area, where the area behind "AMC" and behind the "Military Hospital" has no access in the sewage system, whereas most of the area in "Bregu i Lumit" is filled with septic holes.

As for the road signs, an intervention is necessary in some areas in order to improve it and put up road signs in places they are missing, also the road lightening system is partial or totally lacks in some parts of the roads. In these recent years, the situation is changing for the better, and this fact is verified by the numerous projects where we can mention that of 2003, where several projects were concluded such as the extension of the water supply system and sewages in Koder-Kamez amounting to 80 million ALL, even in Bregu i Lumit, a project amounting to 45 million ALL; the project of Lapraka area started in 2010 and consisted in the reconstruction of some road segments in the area. There are around $7 \mathrm{~km}$ of road, which were rehabilitated in the area, such as "Gjergj Legisi", "Lord Bajron", "Pandi Dardha", "Vangjeli Noti", "Marin Barleti", "Riza Kuka", "Gjergj Kastrioti", "Rexhep Preza".

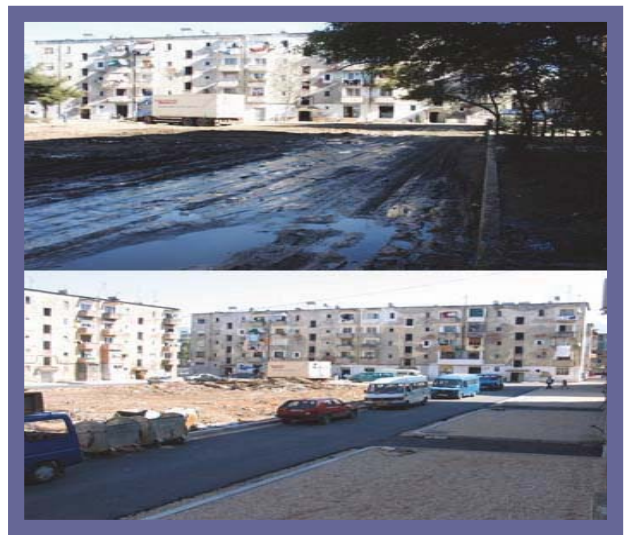

Photo 1: Views from the street rehabilitations in Borough 11

It is the duty of the governance of all the levels not to allow the degradation of the situation to the point that people lose hope for their lives and their children`s lives' improvement. The normal habitation conditions, infrastructure, enhance the life quality and as a consequence they encourage the contribution of the citizens for a further development. The participation of the community in the daily activity, even in the short and long term planning, is essential. The individuals' education and qualification level is of great importance in the position of a simple citizen, member of the community and professionals as well. 


\section{Conclusions}

$>$ The rapid increase of the population number was accompanied with a boom of constructions and various economic activities. After 1990, we have an increasing number of buildings which give the area the view of one of the most suburban typical areas of Tirana, by creating suburban neighborhoods that lack urban planning.

> The human's activity is intensified in the exploitation of the natural resources. Instead of surfaces with fruit trees, now one may see endless constructions, from one storey buildings to 10-12 storey ones.

$>$ As for the habitation conditions such as the supply with drinking water, the number of higene and sanitary equipment, the use of electric appliances, and the possession of a car, are in a non satisfactory level.

$>$ Green spaces for relaxing and unwinding as well as the functioning of a cinema are necessary for the area residents.

\section{References}

Surveys

Tirana Municipality, Statistics Bulletins 2005, 2006, 2008, 2009, 2010

Borough 11, Urbanity Office, Registry Office, different materials

INSTAT "The registration of the population and residences ", April 2001

INSTAT Maps of poverty and inequality in Albania, 2004 